\title{
Direct evidence of a ester linkages between lignin and glucuronoxylan that reveal the robust heteropolymeric complex in plant cell walls
}

Hiroshi Nishimura ( $\square$ nishimura.hiroshi.j03@kyoto-u.jp )

Kyoto University

Kazuma Nagata

Kyoto University

Takashi Nagata

Kyoto University

Masato Katahira

Kyoto University

Takashi Watanabe

Kyoto University

Article

Keywords:

Posted Date: February 8th, 2022

DOI: https://doi.org/10.21203/rs.3.rs-1327348/v1

License: (c) (i) This work is licensed under a Creative Commons Attribution 4.0 International License. Read Full License 
2 Direct evidence of $\alpha$ ester linkages between lignin and glucuronoxylan that reveal the robust heteropolymeric complex in plant cell walls

5 Hiroshi Nishimura*1, Kazuma Nagata ${ }^{2}$, Takashi Nagata $^{2}$, Masato Katahira $^{2}$ and Takashi

$6 \quad$ Watanabe $* * 1$

$7 \quad{ }^{1}$ Research Institute for Sustainable Humanosphere (RISH), Kyoto University, Uji 611-0011, 8 Japan.

$9 \quad{ }^{2}$ Institute of Advanced Energy (IAE), Kyoto University, Uji 611-0011, Japan.

11 * nishimura.hiroshi.j03@kyoto-u.jp

$12 * *$ twatanab@rish.kyoto-u.ac.jp

15 Conclusive evidence of $\alpha$-ester linkages between lignin and glucuronoxylan was obtained by advanced multi-dimensional NMR. 
All vascular plants have lignin that interacts with polysaccharides in cell walls; however, the chemical structure of covalent lignin-carbohydrate (L-C) linkages remains unresolved because of

21 the small number of L-C linkage relative to the polymer main chain. Sample isolation that 22 predominantly maintains intact L-C linkages followed by advanced multi-dimensional NMR 23 showed that the critical L-C linkage between lignin and xylan involves the $\alpha$-position of the $\beta$ 24 aryl ether unit of lignin and the sixth position of the glucuronic acid residue of 4-O-methyl 25 glucuronoxylan. The L-C ester linkages occur primarily at the $\alpha$-position of lignin, supporting a theoretical synthetic pathway through a quinone methide intermediate. In contrast, the conventional $\gamma$-L-C ester was undetectable, indicating that this linkage is not the primary type. Instead, the $\gamma$-acetyl-substituted lignin coexisted. The results on primary L-C linkages contribute to plant physiology and biology and advance research into biomass conversion. 
Structural elucidation of lignin-carbohydrate (L-C) linkages is a central challenge for understanding the mechanism of plant cell wall formation and for strategic molecular breeding of plants with controlled degradability and rigidity, which are key factors considered in plant biomass conversion and wood utilisation. Here we show the principal ester linkage between lignin and xylan (hemicellulose) involves the $\alpha$-position of lignin $\beta$-ether units rather than the previously proposed $\gamma$-position. Glucuronoxylan forms a covalent bond with lignin to yield an amorphous three-fold screw conformation. In lignin-carbohydrate complexes (LCCs), acetylsubstitution at the 3-position of xylan and glucuronic-substitution at the 2-position of xylan is the main side-chain substitution (Fig. 1). We discuss the agreement between a theoretical synthetic pathway via the quinone methide intermediate and the difficulty of rearranging $\alpha$ - to $\gamma$ - in natural macromolecules.

Plant biomass is the most abundant natural polymer on earth. Conversion and use of plant biomass to produce value-added chemicals, biofuels, and materials are indispensable to a sustainable society ${ }^{1}$. The plant cell wall is principally composed of cellulose, hemicelluloses, and lignin. Lignin is an aromatic polymer that is universally conserved in vascular plants. The plant cell wall formation starts with the biosynthesis of cellulose microfibrils. Hemicelluloses are assembled into microfibrils with different orientations. Lignin is later deposited into the polysaccharide matrix by dehydrogenative polymerisation of monolignols. Lignin is a hydrophobic polymer that binds covalently to hydrophilic polysaccharides, hemicelluloses, to form an amphipathic structure called the lignin-carbohydrate complex (LCC). This complex gives the plant cell walls rigidity by interfacing the polymers with different physicochemical properties $^{2}$. LCCs have potential use as amphiphilic polymers, UV absorbers ${ }^{3-4}$, and bio-active 
substances $^{5-7}$ in practical applications. Anti-virus ${ }^{8-10}$ activities of LCCs have interesting physiological activities.

Ester bonds between glucuronoxylan and lignin are the major L-C linkage in plant cell walls, especially in hardwood and herbaceous plants ${ }^{2}$. The complex structure of hemicelluloses and lignin give rise to the robustness and flexibility of plant cell walls ${ }^{11,12}$. Bundles of cellulose microfibrils are coated with xylan-lignin complexes and cross-linked by glucomannan in wood cell walls ${ }^{12,13}$. Acetyl groups distributed in the xylan main chain increase affinity to cellulose by controlling the helical structure of xylan. The two-fold screw xylan is spatially close to cellulose, adheres to the hydrophilic surface of cellulose microfibrils, and has the same rigidity as cellulose. Conversely, three-fold screw xylan is more amorphous and probably interacts with $\operatorname{lignin}^{14-17}$. The hydrophobicity of acetyl groups also increases affinity to lignin.

Previous studies have revealed covalent linkages between glucuronoxylan and lignin, e.g., IR ${ }^{18}$, alkaline degradation ${ }^{19}$, sodium borohydride reduction ${ }^{20}$, and DDQ oxidation ${ }^{21,22}$. Recently, microbial glucuronic acid esterases were used to cleave the L-C ester bonds to facilitate disintegration of plant cell walls in biomass conversion applications ${ }^{23-30}$. Using specific enzymes that cleave the ester bond is an attractive approach for both characterising L-C bonds and biomass conversion; however, definitive data defining the binding sites have not been reported.

Two-dimensional (2D) NMR is a promising approach to identify covalent linkages between lignin and carbohydrates. Currently, there are four different L-C bonds, $\alpha$-ether (benzyl ether), $\alpha$-ester (benzyl ester), $\gamma$-ester, and phenyl glycoside, have been reported based on ${ }^{1} \mathrm{H}-{ }^{13} \mathrm{C}$ heteronuclear single quantum coherence (HSQC) correlations $^{31-37}$. As for ester-type L-C linkages, Balakshin et al. ${ }^{31,32}$ proposed a significant presence of $\gamma$-esters instead of $\alpha$-esters in 
76 pine LCC. In contrast, Yuan et al. ${ }^{37}$ reported that the $\gamma$-ester signal in 2D NMR data of poplar

77 LCC was indeterminable. The conclusions of these studies are based on a comparison of

78 chemical shifts between model compounds and LCC fractions. However, the chemical shifts of

79 the relevant signals are not identical to those of synthetic model compounds. Furthermore, the

80 possibility of misassignment of the signals because of severe overlap with signals from other

81 unidentified compounds cannot be excluded. Thus, the purity, mild LCC sample preparation

82 conditions, and long-range correlated NMR experiments are necessary to solve these issues, as

83 reported for $\beta$-ether bonds between lignin and acetylglucomannan ${ }^{38}$. 


\section{Results}

This study determined the principal ester linkages between lignin and xylan (hemicellulose) at the $\alpha$-position of lignin $\beta$-ether units. A conceptual drawing of lignocellulosic fibre in hardwood cell walls focusing on the covalent L-C $\alpha$-ester linkage and a chemical structural model are shown in Fig. 1.

LCC sample preparation. Fractionation procedures under mild conditions are critical because L-C ester linkages in extracted LCCs are susceptible to denaturation, including acyl migration. Here, we avoided conditions, such as strong mechanical milling, metal ion contaminations, high temperature, and strong acid or alkaline treatments. The isolation scheme is shown in Extended

Data Fig. 1. (see method section and caption in Extended Data Fig. 1). Wood powder was ballmilled in an agate pot, filled with nitrogen under the control of $60^{\circ} \mathrm{C}$ (Extended Data Fig. 2). The crude extracted "LCC-DMSO" was treated with hemicellulase. The soluble liquid fraction "LCC-EL" showed the L-C NMR signals followed by purification, however, too small quantities for advanced NMR experiments. Fortunately, "LCC-ER-AL80", extracted with methanol/water $(8 / 2, \mathrm{v} / \mathrm{v})$ from the precipitate fraction "LCC-ER", was an ideal LCC separated using the solubility differences.

Determination of the L-C $\alpha$-ester linkage structure by multi-dimensional NMR. The LCCER-AL80 was analysed by ${ }^{1} \mathrm{H}-{ }^{13} \mathrm{C}$ HSQC NMR (Fig. 2). We succeeded in assigning signals to $\alpha$-ester-type LCC by multi-dimensional NMR analysis (Extended Data Table. 1). Signals related to the L-C linkage between the $\alpha$-position of the $\beta$-aryl ether unit of the lignin and the $6^{\prime}$ of the glucuronic acid residue of 4'- $O$-methyl glucuronoxylan are shown in Fig. $2 \mathbf{b}$. 
The $\alpha$-CH correlation of $\alpha$-ester-type LCC in HSQC spectra is composed of three signals, I- $\alpha$

$107(\delta \mathrm{H} / \delta \mathrm{C}=5.88 \mathrm{ppm} / 74.4 \mathrm{ppm}), \mathrm{II}-\alpha(\delta \mathrm{H} / \delta \mathrm{C}=6.08 \mathrm{ppm} / 75.2 \mathrm{ppm})$, and III- $\alpha\left(\delta_{\mathrm{H}} / \delta \mathrm{C}=6.00\right.$

108

109

110 $\mathrm{ppm} / 75.5 \mathrm{ppm}$ ) (Fig. 3a). The $\beta$-CH correlations of $\alpha$-ester-type LCC overlapped with the signals from the $\beta$-position of the lignin $\beta-O-4$ ' subunit in the HSQC spectrum (Fig. 3a). We succeeded in assigning the $\beta$-position signals accurately using a 3D TOCSY-HSQC spectrum, I- $\beta\left(\delta_{\mathrm{H}} / \delta_{\mathrm{C}}=\right.$ $4.48 \mathrm{ppm} / 82.9 \mathrm{ppm})($ Fig. 3b $)$, II- $\beta\left(\delta_{\mathrm{H}} / \delta \mathrm{C}=4.28 \mathrm{ppm} / 83.7 \mathrm{ppm}\right)($ Fig. $3 \mathbf{c})$, and III- $\beta\left(\delta_{\mathrm{H}} / \delta_{\mathrm{C}}=\right.$ $4.28 \mathrm{ppm} / 83.9 \mathrm{ppm})$ (Fig. 3d).

The $\gamma-\mathrm{CH}_{2}$ correlations of $\alpha$-ester-type LCC were determined from 3D TOCSY-HSQC (Fig. 3e) and $2 \mathrm{D}{ }^{1} \mathrm{H}-{ }^{13} \mathrm{C} \mathrm{HMBC}(\mathrm{HMBC})($ Fig. 3f $)$ spectra as $\gamma_{1}(\delta \mathrm{H} / \delta \mathrm{C}=3.55 \mathrm{ppm} / 62.0 \mathrm{ppm}) . \gamma_{2}$ $\left(\delta_{\mathrm{H}} / \delta_{\mathrm{C}}=3.83 \mathrm{ppm} / 62.0 \mathrm{ppm}\right)$ was assigned using HSQC-TOCSY and HMBC spectra. In the HMBC spectrum, correlation signals between the $\alpha$-proton of the L-C ester to the $\beta$ - and $\gamma$ carbons of the lignin $\beta$-aryl ether unit and syringyl aromatic ring $\left(\mathrm{S}_{1}\right.$ and $\left.\mathrm{S}_{2,6}\right)$ were observed (Fig. 3f). The aromatic ring proximity to the $\alpha$-position was mainly the syringyl lignin. Although weak, a signal representing a correlation between LC $\alpha$-est-II $\alpha$ and the guaiacyl lignin unit was also observed (Fig. 3f).

A significant correlation between the $\alpha$ proton of $\alpha$-ester-type LCC and the carbonyl carbon $(\delta \mathrm{C}$ $=169.7$ ppm) was observed (Fig. 3f). This carbonyl carbon resonates upfield when compared with the carbonyl carbon of the acetylated derivative of lignin $(\delta \mathrm{C} \approx 170.2 \mathrm{ppm})$. Combined with the correlation data described in Fig. 6, this correlation was determined to be the carbonyl carbon at the 6 -position of glucuronic acid. 
The 4'-O-methyl glucuronoxylan moiety of $\alpha$-ester-type LCC was assigned by through-bond correlations from 1' to 5', in the 3D TOCSY-HSQC spectrum (Fig. 4 a-f, see caption). A critical correlation indicating the presence of the $\alpha$-ester L-C linkage is the correlation between the $\alpha-\mathrm{CH}$ of the lignin $\beta-O-4^{\prime}$ subunit and the ester carbonyl $(\mathrm{C}=\mathrm{O})$ at the 6-position of the glucuronic acid residue in 4'-O-methyl-glucuronoxylan (Fig. 5). Starting from the $\alpha$-CH correlation signal of $\alpha$ ester-type LCC shown in the HSQC spectrum (Fig. 5a), the $\alpha-\mathrm{CH}$ proton $\left(\delta_{\mathrm{H}}=5.9\right.$ and $\left.6.0 \mathrm{ppm}\right)$ was correlated to the carbonyl carbon of glucuronoxylan, 6'-GlcA $(\delta \mathrm{C}=169.7 \mathrm{ppm})$ in the HMBC spectrum (Fig. 5b). Additionally, the L-C ester carbonyl $(\mathrm{C}=\mathrm{O}, \delta \mathrm{c}=169.7 \mathrm{ppm})$ correlated to $5^{\prime}-\mathrm{CH}$ of glucuronate $\left(5^{\prime}-\mathrm{GluA}, \delta_{\mathrm{H}}=4.80 \mathrm{ppm}\right)$ in the HMBC spectrum (Fig. 5b), which confirms the $\alpha$-ester L-C linkage to 4'- $O$-methyl-glucuronoxylan.

Notably, the chemical shift $(4.80 \mathrm{ppm})$ of the 5'-GluA hydrogen was near identical to the chemical shift of the acetyl-substituted xylan at the 3-position (Xyl-3-Ac), as shown in Fig. 5a. We should discriminate between $\alpha$-ester-type LCC and acetyl-substituted xylan at the 3-position (Xyl-3-Ac) before drawing the final conclusion. Correlations derived from ${ }^{2} J_{\mathrm{CH}}$ and ${ }^{3} J_{\mathrm{CH}}$ spincouplings are observed in HMBC, whereas, in 1,1-ADEQUATE, only ${ }^{2} J_{\mathrm{CH}}$ spin-couplings are observed $^{39}$. The correlation signal between the hydrogen of 5'-GluA and ester carbonyl $(\mathrm{C}=\mathrm{O})$ was observed in the 1,1-ADEQUATE spectrum (Fig. 5c), which confirms $\alpha$-ester-type LCC and excludes the possibility of the alternative acetyl-substituted xylan at the 3-position. Correlations $(\sim \delta \mathrm{H} / \delta \mathrm{C}=4.8 \mathrm{ppm} / 170.4 \mathrm{ppm})$ derived from the acetyl-substituted xylan at the 3-position (Xyl-3Ac) as a ${ }^{3} J_{\mathrm{CH}}$ coupling were observed in the HMBC spectrum (Fig. $\left.5 \mathbf{b}\right)$.

$$
\gamma \text {-Ester-type LCC was proposed by Balakshin et al. The signals at } \delta \mathrm{H} / \delta \mathrm{C}=62-65 \mathrm{ppm} / 4.0-4.5
$$
ppm were attributed to $\gamma$-ester-type $\mathrm{LCC}^{32}$. For LCC-ER-AL80, correlations between protons in 
148 the region of 4.0-4.5 ppm and carbonyl carbons $(\delta \mathrm{C}=170.2 \mathrm{ppm})$ were observed (Fig. $5 \mathbf{b}$, peaks

149 indicated by beige arrow). This observation suggests the presence of $\gamma$-ester-type LCC;

150 however, this is incorrect, as explained below. The correlations between protons in the 4.0-4.5

151 ppm region and carbonyl carbons (170.2 ppm) are not observed in 1,1-ADEQUATE (Fig. 5c).

152 This observation indicates that the correlations observed in the HMBC spectrum (Fig. 5b) are not

153 derived from ${ }^{2} J_{\mathrm{CH}}$ spin couplings but ${ }^{3} J_{\mathrm{CH}}$ spin couplings. Therefore, these correlations observed

154 in the HMBC spectrum (Fig. 5b, beige arrow) do not originate from $\gamma$-ester-type LCC in which

$155{ }^{2} J_{\mathrm{CH}}$ spin couplings are present, but from $\gamma$-acetyl lignin in which ${ }^{3} J_{\mathrm{CH}}$ spin coupling should be

156 present. Thus, the presence of $\gamma$-ester type LCC is refuted at the detectable level of long-range

157 correlated NMR.

158 The above results showed that we successfully assigned the ester linkage between the $\alpha$ -

159 position of the $\beta-O-4^{\prime}$ subunit of lignin and the 6-position of the glucuronic acid residue in $4^{\prime}-O$ -

160 methyl-glucuronoxylan. 


\section{Discussion}

163 Plant secondary cell walls are a highly complex composite of cellulose, hemicelluloses (mainly

164 xylan and glucomannan), and lignin. The supramolecular network of these macromolecules

165 renders the cell walls with sufficient mechanical strength and rigidity. LCCs serve as a

166 compatibiliser between hydrophobic lignin and hydrophilic polysaccharides in the cell wall

167 network. Thus, L-C linkages restrict the degradation of plant cell walls by chemical and

168 enzymatic reactions. Considerable research has been devoted to developing versatile pre-

169 treatment methods and genetically engineered plants with cell wall structures suitable for

170 biomass conversion. The efficient conversion of plant biomass based on an accurate

171 understanding of the cell wall structure is essential for lignocellulosic biorefinery.

172 Lignin binds to polysaccharides through covalent and non-covalent linkages that have been 173 studied in detail using solid-state $\mathrm{NMR}^{16,17}$, and the interaction between cellulose and xylan

174 probably involves a hydrophobic surface formed by a two-fold helical screw symmetry with a

175 regular pattern of xylan substituted by acetate or glucuronic acid ${ }^{17}$. In stark contrast to the strong

176 interaction between xylan and lignin, direct interactions between cellulose and lignin are weak

177 and not a major factor responsible for the strength of cell walls. Solid-state NMR and simulation

178 results showed that lignin is closely associated with xylan by electrostatic and hydrophobic

179 interactions and that a distorted xylan structure is advantageous for lignin binding ${ }^{16,17 .}$

180 Previous studies with model compounds have assigned the linkage between glucuronic acid and

181 the lignin dimer ${ }^{40-42}$; however, NMR chemical shifts of signals representing these model

182 compounds differ from those of the natural polymer. Recently, an ester-type L-C linkage at the 
183

184

185

186

187

188

189

190

191

192

193

194

195

196

197

$\alpha$-position was reported ${ }^{43}$. However, the correlation with the carbonyl carbon in the HMBC spectrum was around $196 \mathrm{ppm}$, indicating a correlation with an aldehyde rather than glucuronic acid. Thus, this correlation is not derived from $\alpha$-ester type LCC and represents a different chemical moiety.

Here, we clearly showed the existence of L-C linkages between the $\alpha$-position of the $\beta-O-4^{\prime}$ lignin unit, which is the main structure of lignin, and the 6-position of glucuronic acid of glucuronoxylan. Preventing artificial denaturation of the sample during the ball-milling step was critical in the sample preparation process. Thus, we performed ball-milling under mild conditions by maintaining the temperature under $60^{\circ} \mathrm{C}$, replacing the air with a nitrogen atmosphere after evacuation, and using an agate stone pot. The crude sample, LCC-DMSO, gave rise to the $\mathrm{C}-\mathrm{H}$ correlation signal at the $\alpha$-position of the L-C-ester in the HSQC spectrum, indicating that $\alpha$-ester-type LCC exists in the natural wood cell wall (Extended Data Fig. 3).

Interestingly, this L-C-ester signal was not seen in samples treated by vibro-ball-milling in a stainless-steel pot for $24 \mathrm{~h}$, indicating mild mechanical processing and non-denaturing extraction and fractionation are critical for isolating $\alpha$-ester-type LCC.

The $\beta$-position correlation signal of LC-ester overlapped with other signals. Thus, a 3D TOCSY-HSQC spectrum was used to overcome this issue. We succeeded in identifying the $\alpha$ position and $\beta$-position of at least three LC-ester-types with different chemical shifts (Fig. 3a-d) by examining the $\alpha(\mathrm{H})$-position of the LC-ester in the 3D TOCSY-HSQC spectrum. Differences in chemical shifts arose primarily from differences in diastereomers (threo and elythro). HMBC correlations (Fig. 3f) demonstrated that the $\alpha$-position of the L-C-ester locates proximal to the syringyl lignin aromatic unit. The HMBC correlation between the $\alpha$-position $\mathrm{H}$ of the LC-ester 
and the carbon at the 1-position of the lignin aromatic ring resonated at $134.7 \mathrm{ppm}\left(\delta_{\mathrm{H}} / \delta_{\mathrm{C}}=6.00\right.$ $\mathrm{ppm} / 134.7 \mathrm{ppm})$ in addition to the syringyl nucleus $(\mathrm{S} 1)$ found at $132.7 \mathrm{ppm}\left(\delta_{\mathrm{H}} / \delta \mathrm{C}=5.89\right.$ ppm/132.7 ppm), derived from the phenolic terminal unit or the guaiacyl nucleus.

$$
\text { Xylans are substituted at the 2- or 3-position with acetyl groups, and some are acetylated at }
$$
both the 2-and 3-positions. The pattern of this modification has been identified to occur at even numbers, and the two-fold screw structure plays an essential role in the interaction with cellulose $^{16,17,44}$. HSQC spectra (Fig. 2, Extended Data Fig. 3a, c) of LCC-ER-AL80 clearly showed a lower frequency of acetylation of glucuronoxylan than the crude extracts, LCC-DMSO (Extended Data Fig. 3b). In addition, acetylation occurred primarily at the 3-position of xylan, whereas modification of the glucuronic acid side chain occurred at the 2-position of xylan (Extended Data Fig. 3c).

This xylan substituent pattern supports the structure that facilitates the formation of threefold helical screw conformations ${ }^{45}$. From molecular dynamics simulations, acetylation at the 2position stabilises the two-fold helical screw conformation, and xylan interacts tightly with cellulose, whereas acetylation at the 3-position takes an amorphous structure as the three-fold helical screw conformation and xylan interacts readily with lignin ${ }^{45}$.

Ester bonds between lignin and the 4- $O$-methyl glucuronic acid residue in xylan are formed by nucleophilic addition of the carboxyl group to a quinone methide intermediate formed by the radical coupling of $\beta$ - and phenoxy radicals of monolignols and those from growing lignin chains. As expected from the resonance structure, the $\alpha$-position of the quinone methide is electrophilic and reacts with the nucleophile, the carboxyl group of 4- $O$-methyl-glucuronic acid. 
Therefore, the 4-O-methyl-glucuronic acid residue ester bonds are formed exclusively at the $\alpha$ position of phenyl propane units. An acidic $\mathrm{pH}$ favours the reaction of quinone methide with glucuronic acid ${ }^{46}$. Biosynthesis of secondary cell walls starts by forming cellulose and hemicelluloses. Xylan has two and three helical structures. Two-fold extended xylan accounts for $\sim 70 \mathrm{~mol} \%$ of the polyose bridges in cellulose microfibrils of plant cell walls ${ }^{16}$. Lignin is deposited with a considerable delay after forming the tightly packed hemicellulose-cellulose matrix and associates with the three-fold xylan helix through electrostatic interactions.

Therefore, it is unlikely that all ester L-C bonds in secondary cell walls migrate from the $\alpha$ - to $\gamma$ position in the tightly packed polysaccharide bridges, which are finally fulfilled with lignin. Migration of glucuronate from the $\alpha$ - to $\gamma$-position was first reported by Toikka ${ }^{40,41}$ based on the study of synthetic L-C ester model compounds. However, this hypothesis was proposed by an in vitro solution reaction using a low molecular mass model. As discussed, in plant cell walls, the aromatic polymer, lignin, is densely deposited in the high molecular weight polysaccharide network where xylan chains fold onto the surface of cellulose fibrils through hydrogen bonding, which makes migration far more difficult than that observed in solution reactions of model compounds (Fig. 6).

The conclusive NMR assignments herein clearly showed that the $\alpha$-ester rather than the $\gamma$-ester is the major bond between glucuronoxylan and lignin, as expected from the biosynthetic pathway of secondary cell walls, critically revealing that previous studies reporting the $\gamma$-ester may include misassigned NMR signals, which were conducted only by comparison of chemical shifts with model compounds, or migration after or during the extraction process of LCCs. 
249 Multi-dimensional NMR showed that the L-C $\alpha$-ester linkage in LCC is mediated by lignin and 250 glucuronoxylan. The linkage was formed between the $\alpha$-position of the $\beta-O-4^{\prime}$ lignin unit and 251 the 6-position of the 4-O-methyl glucuronic substituent of glucuronoxylan. The dominant 252 proximal lignin unit was syringyl, and the primary acetyl substituent of xylan in LCC was at the 253 3-position. Analysis of HMBC and 1,1-ADEQUATE spectra revealed clear evidence of L-C 254 linkages at the $\alpha$-position of lignin $\beta-O-4^{\prime}$ units. However, no correlation was observed at the $\gamma-$ 255 position. Instead, $\gamma$-acetyl-substituted lignin was identified. We have elucidated that the major 256 ester-type LCC is the $\alpha$-ester instead of the $\gamma$-ester, which amends conventional principles.

257 Understanding the covalent L-C-ester linkage contributes to plant sciences and facilitates 258 research into biomass conversion, refineries, biotechnology, and enzymology. 


\section{Acknowledgements}

261 This study was supported in part by JSPS KAKENHI (16H06210, 21H02258), JST-Mirai

262 Program (JPMJMI21EG) from Japan Science and Technology Agency, Japan Association for

263 Chemical Innovation Foundation, The Kyoto University Foundation, mission research program

264 (M5-2-4), and ADAM collaboration program of RISH, ZE joint usage research program of IAE,

265 Kyoto University. We thank Edanz (https://jp.edanz.com/ac) for editing a draft of this

266 manuscript.

267

268 Author Contributions

269 H.N., M.K., and T.W. designed the research. H.N., T.W., K.N., and T.N. performed the

270 research. H.N. and T.W. wrote the manuscript. T.N. and M.K. refined the manuscript. 


\section{References}

1. Baral NR, Sundstrom ER, Das L, Gladden J, Eudes A, Mortimer JC, et al. Approaches for More Efficient Biological Conversion of Lignocellulosic Feedstocks to Biofuels and Bioproducts. ACS Sustain Chem Eng 2019, 7(10): 9062-9079.

2. Koshijima T, Watanabe T. Association between lignin and carbohydrates in wood and other plant tissues, Springer Series in Wood Science. Springer, 2003.

3. Nanbu T, Shimada J, Kobayashi M, Hirano K, Koh T, Machino M, et al. Anti-UV activity of lignincarbohydrate complex and related compounds. In Vivo 2013, 27(1): 133-139.

4. Sakagami H, Sheng H, Okudaira N, Yasui T, Wakabayashi H, Jia J, et al. Prominent Anti-UV Activity and Possible Cosmetic Potential of Lignin-carbohydrate Complex. In Vivo 2016, 30(4): 331-339.

5. Kushida T, Makino T, Tomomura M, Tomomura A, Sakagami H. Enhancement of Dectin-2 gene expression by lignin-carbohydrate complex from Lentinus edodes mycelia extract (LEM) in a mouse macrophage-like cell line. Anticancer Res 2011, 31(4): 1241-1248.

6. Sakagami H, Kushida T, Oizumi T, Nakashima H, Makino T. Distribution of lignin-carbohydrate complex in plant kingdom and its functionality as alternative medicine. Pharmacol Ther 2010, 128(1): 91-105.

7. Tsuji R, Ikado K, Fujiwara D. Modulation of Innate Immunity by lignin-Carbohydrate, a Novel TLR4 Ligand, Results in Augmentation of Mucosal IgA and Systemic IgG Production. Int J Mol Sci 2017, 19(1).

8. Li R, Ouda R, Kimura C, Narita R, Nishimura H, Fujita T, et al. Conversion of Beech Wood into Antiviral Lignin-Carbohydrate Complexes by Microwave Acidolysis. Acs Sustain Chem Eng 2021, 9(28): 92489256.

9. Lee JB, Yamagishi C, Hayashi K, Hayashi T. Antiviral and immunostimulating effects of lignincarbohydrate-protein complexes from Pimpinella anisum. Biosci Biotechnol Biochem 2011, 75(3): 459465 .

10. Sakagami H, Kawano M, Thet MM, Hashimoto K, Satoh K, Kanamoto T, et al. Anti-HIV and immunomodulation activities of cacao mass lignin-carbohydrate complex. In Vivo 2011, 25(2): 229-236.

11. Giummarella N, Pu YQ, Ragauskas AJ, Lawoko M. A critical review on the analysis of lignin carbohydrate bonds. Green Chem 2019, 21(7): 1573-1595.

12. Terashima N, Yoshida M, Hafren J, Fukushima K, Westermark U. Proposed supramolecular structure of lignin in softwood tracheid compound middle lamella regions. Holzforschung 2012, 66(8): 907-915.

13. Cosgrove DJ, Jarvis MC. Comparative structure and biomechanics of plant primary and secondary cell walls. Front Plant Sci 2012, 3: 204.

14. Busse-Wicher M, Grantham NJ, Lyczakowski JJ, Nikolovski N, Dupree P. Xylan decoration patterns and the plant secondary cell wall molecular architecture. Biochem Soc Trans 2016, 44(1): 74-78.

15. Simmons TJ, Mortimer JC, Bernardinelli OD, Poppler AC, Brown SP, deAzevedo ER, et al. Folding of xylan onto cellulose fibrils in plant cell walls revealed by solid-state NMR. Nat Commun 2016, 7: 13902.

16. Kang X, Kirui A, Dickwella Widanage MC, Mentink-Vigier F, Cosgrove DJ, Wang T. Ligninpolysaccharide interactions in plant secondary cell walls revealed by solid-state NMR. Nat Commun 2019, 10(1): 347 . 
17. Terrett OM, Lyczakowski JJ, Yu L, Iuga D, Franks WT, Brown SP, et al. Molecular architecture of softwood revealed by solid-state NMR. Nat Commun 2019, 10(1): 4978.

18. Wang P.Y. BHI. Uronic acid ester groups in some softwoods and hardwoods Tappi 1967(50): 123-124.

19. Das NN, Das S.C., Mukherjee, A. K. On the ester linkage between lignin and 4-O-methyl-D-glucurono-Dxylan in jute fiber (Corchorus capsularis). Carbohdr Res 1984, 127: 345-348.

20. Takahashi N, Koshijima, T. Ester linkages between lignin and glucuronoxylan in a lignin-carbohydrate complex from beech (Fagus crenata) wood. Wood Sci Technol 1988, 22: 177-189.

21. Imamura T, Watanabe T, Kuwahara M, Koshijima T. Ester Linkages between Lignin and Glucuronic-Acid in Lignin-Carbohydrate Complexes from Fagus Crenata. Phytochemistry 1994, 37(4): 1165-1173.

22. Watanabe T, Koshijima T. Evidence for an Ester Linkage between Lignin and Glucuronic-Acid in Lignin Carbohydrate Complexes by DDQ-Oxidation. Agric Biol Chem 1988, 52(11): 2953-2955.

23. d'Errico C, Jorgensen JO, Krogh KBRM, Spodsberg N, Madsen R, Monrad RN. Enzymatic Degradation of Lignin-Carbohydrate Complexes (LCCs): Model Studies Using a Fungal Glucuronoyl Esterase from Cerrena Unicolor. Biotechnol Bioeng 2015, 112(5): 914-922.

24. Baath JA, Giummarella N, Klaubauf S, Lawoko M, Olsson L. A glucuronoyl esterase from Acremonium alcalophilum cleaves native lignin-carbohydrate ester bonds. FEBS Lett 2016, 590(16): 2611-2618.

25. Huttner S, Klaubauf S, de Vries RP, Olsson L. Characterisation of three fungal glucuronoyl esterases on glucuronic acid ester model compounds. Appl Microbiol Biotechnol 2017, 101(13): 5301-5311.

26. Huynh H, Ishii N, Matsuo I, Arioka M. A novel glucuronoyl esterase from Aspergillus fumigatus-the role of conserved Lys residue in the preference for 4-O-methyl glucuronoyl esters. Appl Microbiol Biotechnol 2018, 102(5): 2191-2201.

27. Mosbech C, Holck J, Meyer AS, Agger JW. The natural catalytic function of CuGE glucuronoyl esterase in hydrolysis of genuine lignin-carbohydrate complexes from birch. Biotechnol Biofuels 2018, 11: 71.

28. Mosbech C, Holck J, Meyer A, Agger JW. Enzyme kinetics of fungal glucuronoyl esterases on natural lignin-carbohydrate complexes. Appl Microbiol Biotechnol 2019, 103(10): 4065-4075.

29. Lin MI, Hiyama A, Kondo K, Nagata T, Katahira M. Classification of fungal glucuronoyl esterases (FGEs) and characterization of two new FGEs from Ceriporiopsis subvermispora and Pleurotus eryngii. Appl Microbiol Biotechnol 2018, 102(22): 9635-9645.

30. Ernst HA, Mosbech C, Langkilde AE, Westh P, Meyer AS, Agger JW, et al. The structural basis of fungal glucuronoyl esterase activity on natural substrates. Nat Commun 2020, 11(1): 1026.

31. Balakshin M, Capanema E, Gracz H, Chang HM, Jameel H. Quantification of lignin-carbohydrate linkages with high-resolution NMR spectroscopy. Planta 2011, 233(6): 1097-1110.

32. Balakshin MY, Capanema EA, Chang HM. MWL fraction with a high concentration of lignin-carbohydrate linkages: Isolation and 2D NMR spectroscopic analysis. Holzforschung 2007, 61(1): 1-7.

33. Lawoko M, Henriksson G, Gellerstedt G. Structural differences between the lignin-carbohydrate complexes present in wood and in chemical pulps. Biomacromolecules 2005, 6(6):3467-3473.

34. Miyagawa Y, Kamitakahara H, Takano T. Fractionation and characterization of lignin-carbohydrate complexes (LCCs) of Eucalyptus globulus in residues left after MWL isolation. Part II: Analyses of xylanlignin fraction (X-L). Holzforschung 2013, 67(6): 629-642. 
35. Miyagawa Y, Mizukami T, Kamitakahara H, Takano T. Synthesis and fundamental HSQC NMR data of monolignol beta-glycosides, dihydromonolignol beta-glycosides and p-hydroxybenzaldehyde derivative beta-glycosides for the analysis of phenyl glycoside type lignin-carbohydrate complexes (LCCs). Holzforschung 2014, 68(7): 747-760.

36. Tarasov D, Leitch M, Fatehi P. Lignin-carbohydrate complexes: properties, applications, analyses, and methods of extraction: a review. Biotechnol Biofuels 2018, 11: 269.

37. Yuan TQ, Sun SN, Xu F, Sun RC. Characterization of Lignin Structures and Lignin-Carbohydrate Complex (LCC) Linkages by Quantitative C-13 and 2D HSQC NMR Spectroscopy. J Agr Food Chem 2011, 59(19): 10604-10614.

38. Nishimura H, Kamiya A, Nagata T, Katahira M, Watanabe T. Direct evidence for $\alpha$ ether linkage between lignin and carbohydrates in wood cell walls. Scientific Reports 2018, 8(1): 6538.

39. Hilton BD, Martin GE. Investigation of the experimental limits of small-sample heteronuclear 2D NMR. $J$ Nat Prod 2010, 73(9): 1465-1469.

40. Toikka M, Sipila J, Teleman A, Brunow G. Lignin-carbohydrate model compounds. Formation of lignin methyl arabinoside and lignin methyl galactoside benzyl ethers via quinone methide intermediates. J Chem Soc Perk T 1 1998(22): 3813-3818.

41. Toikka M, Brunow G. Lignin-carbohydrate model compounds. Reactivity of methyl 3-O-(alpha-Larabinofuranosyl)-beta-D-xylopyranoside and methyl beta-D-xylopyranoside towards a beta-O-4-quinone methide. J Chem Soc Perk T 1 1999(13): 1877-1883.

42. Nylander F, Sunner H, Olsson L, Christakopoulos P, Westman G. Synthesis and enzymatic hydrolysis of a diaryl benzyl ester model of a lignin-carbohydrate complex (LCC). Holzforschung 2016, 70(5): 385-391.

43. Sapouna I, Lawoko M. Deciphering lignin heterogeneity in ball milled softwood: unravelling the synergy between the supramolecular cell wall structure and molecular events. Green Chem 2021, 23(9): 33483364.

44. Grantham NJ, Wurman-Rodrich J, Terrett OM, Lyczakowski JJ, Stott K, Iuga D, et al. An even pattern of xylan substitution is critical for interaction with cellulose in plant cell walls. Nat Plants 2017, 3(11): 859865 .

45. Gupta M, Rawal TB, Dupree P, Smith JC, Petridis L. Spontaneous rearrangement of acetylated xylan on hydrophilic cellulose surfaces. Cellulose 2021, 28(6): 3327-3345.

46. Sipilä J, Brunow G. On the Mechanism of Formation of Non-Cyclic Benzyl Ethers During Lignin Biosynthesis Part 3. The Reactivity of a $\beta$ - $O$-4-Type Quinone Methide with Methyl- $\alpha$-D-glucopyranoside in Competition with Vanillyl Alcohol. The Formation and the Stability of Benzyl Ethers between Lignin and Carbohydrates. 1991, 45(s1): 3-8. 


\section{Methods}

The LCC samples were carefully prepared under mild conditions. Samples were kept below $60^{\circ} \mathrm{C}$ throughout the fractionation and extraction procedures. Wiley-milled wood powder was prepared from the sapwood timber of Japanese beech wood (Fagus crenata, buna in Japanese). The isolation scheme is shown in Extended Data Fig. 1. To eliminate extractives, obtained beech wood powder was extracted twice with an ethyl alcohol-toluene mixture (1:2, v/v) with a ratio of $5.3 \mathrm{~L}$ per $1 \mathrm{~kg}$ wood at $60^{\circ} \mathrm{C}$ for $24 \mathrm{~h}$. Next, pectin was removed by extraction with $0.25 \mathrm{w} / \mathrm{v} \%$ aqueous potassium acetate with a ratio of $10 \mathrm{~L}$ per $1 \mathrm{~kg}$ wood at $60^{\circ} \mathrm{C}$ for $24 \mathrm{~h}$. The wood powder was then washed with pure water and acetone, followed by drying. The pre-extracted wood powder was subjected to planetary ball-milling by PULVERISETTE 6 (Fritsch Japan Co. Ltd., Kanagawa, Japan) with an overpot system, as shown in Extended Data Fig. 2. The pot was evacuated, sealed, and replaced with nitrogen gas using an overpot system after evacuation. Heat damage was prevented by inserting a 1.2-min cooling period between 1 min milling intervals to ensure the internal temperature remained below $60^{\circ} \mathrm{C}$, which was checked by an irreversible thermography patch (NiGK Co., Saitama, Japan, shown in Extended Data Fig. 2c). For the milling conditions, $1 \mathrm{~g}$ wood powder and $100 \mathrm{~g}$ of zirconia beads $(\Phi 3 \mathrm{~mm})$ were placed in an agate pot with a capacity of $80 \mathrm{~mL}$. The sample was then milled for $1 \mathrm{~min}$ at $550 \mathrm{rpm}$ and this 1 min milling procedure was repeated 180 times, i.e., $3 \mathrm{~h}$ (net).

Preparation of LCC samples. The ball-milling wood (20 g) was extracted with DMSO (40 $\mathrm{mL})$ in twice with stirring followed by lyophilisation. The extracts $(2.60 \mathrm{~g})$ termed "LCCDMSO" was treated with a polysaccharide-degrading enzyme, hemicellulase cellulosin GM5 (HBI Enzymes Inc., Hyogo, Japan), derived from Aspergillus niger, which was partially purified by ammonium sulfate precipitation and ultrafiltration (Amicon, MWCO 10 kDa, Merck Japam 
Co. Ltd.) before use. The enzyme had $719 \mathrm{kU} / \mathrm{g}$ xylanase activity when beech wood-derived xylan (Nacalai Tesque, Kyoto, Japan) was used as the substrate.

Enzymatic treatment was conducted under the following conditions: LCC-DMSO (2.60 g), acetic acid buffer ( $\mathrm{pH} 4.0,50 \mathrm{mM}, 65 \mathrm{~mL})$, and $1 \mathrm{~g} \mathrm{w} / \mathrm{v} \%$ enzyme at $50^{\circ} \mathrm{C}$ for $80 \mathrm{~h}$ with stirring. After the reaction, the LCC-DMSO was partly hydrolysed and washed with water three times followed by centrifugation to separate supernatant and precipitates, termed soluble liquid fraction "LCCEL" and the residue "LCC-ER". The LCC-ER (2.3 g) was obtained after lyophilisation. A fraction of the obtained sample was dissolved in DMSO- $d 6$ for NMR analysis. The LCC-EL was purified by chromatography using a hydrophobic interaction/size exclusion gel TOYOPEARL HW50 (Tosoh Bioscience LLC, Tokyo, Japan). LCC-ER (2.2 g) was extracted with 60 mL methanol/water $(\mathrm{v} / \mathrm{v}, 8 / 2)$ twice at room temperature for $1 \mathrm{~h}$ with $100 \mathrm{kHz}$ ultrasound irradiation (VS-100III, AS ONE Co. Ltd, Osaka, Japan). The precipitate and supernatant were centrifuged, and the supernatant was collected, followed by evaporation and lyophilisation to obtain a $0.1-\mathrm{g}$ purified LCC sample termed "LCC-ER-AL80".

NMR experiments. Samples were dissolved in $0.5 \mathrm{~mL}$ of DMSO- $d_{6}$ and transferred to an NMR tube (DMS-005TB, Shigemi Co. Ltd., Tokyo, Japan). NMR spectra were recorded at $313 \mathrm{~K}$ using a Bruker AVANCE III $600 \mathrm{MHz}$ spectrometer with a 5-mm TCI cryoprobe. A $1 \mathrm{D}{ }^{1} \mathrm{H}$ NMR spectrum of the sample was acquired using an acquisition time (AQ) of $0.9 \mathrm{~s}$, an interscan delay (D1) of $2.0 \mathrm{~s}$, and 32 scans. The two-dimensional (2D) ${ }^{1} \mathrm{H}-{ }^{13} \mathrm{C}$ HSQC (HSQC) spectrum was recorded using an adiabatic HSQC experiment (Bruker pulse program, hsqceetgpsisp2.2) with the following parameters: AQ, $0.10 \mathrm{~s} ; \mathrm{D} 1,2.0 \mathrm{~s} ; \mathrm{a}^{1} \mathrm{H}$ spectral width of $16 \mathrm{ppm}$, and 165 ppm for ${ }^{13} \mathrm{C}$ with $2048 \times 512$ complex points; 32 scans per increment. The ${ }^{1} J_{\mathrm{CH}}$ used was 145 
$474 \mathrm{~Hz}$. Before Fourier transformation, the data matrices were zero-filled to 1024 points in the ${ }^{13} \mathrm{C}$ 475 dimension and processed with a Gaussian window function in the ${ }^{1} \mathrm{H}$ dimension and a sine-bell 476 square window function in the ${ }^{13} \mathrm{C}$ dimension. The multiplicity-edited HSQC was recorded 477 using the Bruker pulse program, hsqcedetgp. The $2 \mathrm{D}{ }^{1} \mathrm{H}-{ }^{13} \mathrm{C}$ HMBC (HMBC) spectrum was recorded using a magnitude-mode ge-2D HMBC with a low-pass $J$-filter (Bruker pulse program, hmbcgplpndqf). The parameters for this $2 \mathrm{D}$ HMBC were: AQ, $0.12 \mathrm{~s} ; \mathrm{D} 1,1.2 \mathrm{~s}$; a ${ }^{1} \mathrm{H}$ spectral width of $14 \mathrm{ppm}$, and $150 \mathrm{ppm}$ for ${ }^{13} \mathrm{C}$ with $2048 \times 512$ complex points; 48 scans per increment. The 2D HMBC spectra were processed with a sine-bell window function in ${ }^{1} \mathrm{H}$ and ${ }^{13} \mathrm{C}$ dimensions. The three-dimensional (3D) ${ }^{1} \mathrm{H}-{ }^{13} \mathrm{C}$ TOCSY-HSQC spectrum was recorded using the Bruker pulse program, mlevhsqcetgp3d with the following parameters: AQ, $0.07 \mathrm{~s} ; \mathrm{D} 1,1.0 \mathrm{~s}$; a spectral window of $12 \mathrm{ppm}$ for the ${ }^{1} \mathrm{H}$ direct dimension, $58 \mathrm{ppm}$ for ${ }^{13} \mathrm{C}$, and $5.5 \mathrm{ppm}$ for the indirect ${ }^{1} \mathrm{H}$ dimension with $1024 \times 384 \times 64$ complex points; 8 scans per increment; $100 \mathrm{~ms}$ TOCSY spinlock. The 3D spectrum was processed with a sine-bell square window function in all dimensions. 1,1-ADEQUATE spectrum was recorded using the Bruker pulse program, adeq11etgprdsp with the following parameters: AQ, $0.11 \mathrm{~s} ; \mathrm{D} 1,1.5 \mathrm{~s} ; \mathrm{a}^{1} \mathrm{H}$ spectral window of $16 \mathrm{ppm}$, and $80 \mathrm{ppm}$ for ${ }^{13} \mathrm{C}$ with $2048 \times 196$ complex points; 192 scans per increment. The data matrices were zero-filled to 1024 points in the ${ }^{13} \mathrm{C}$ dimension and processed with a Gaussian window function in the ${ }^{1} \mathrm{H}$ dimension and a sine-bell square window function in the ${ }^{13} \mathrm{C}$ dimension. Data processing was performed using standard Bruker Topspin-NMR software (ver. 3.1). The solvent (DMSO) peak was used as an internal chemical shift reference point $\left(\delta_{\mathrm{H}} / \delta_{\mathrm{C}}=\right.$ $2.49 \mathrm{ppm} / 39.6 \mathrm{ppm})$. 


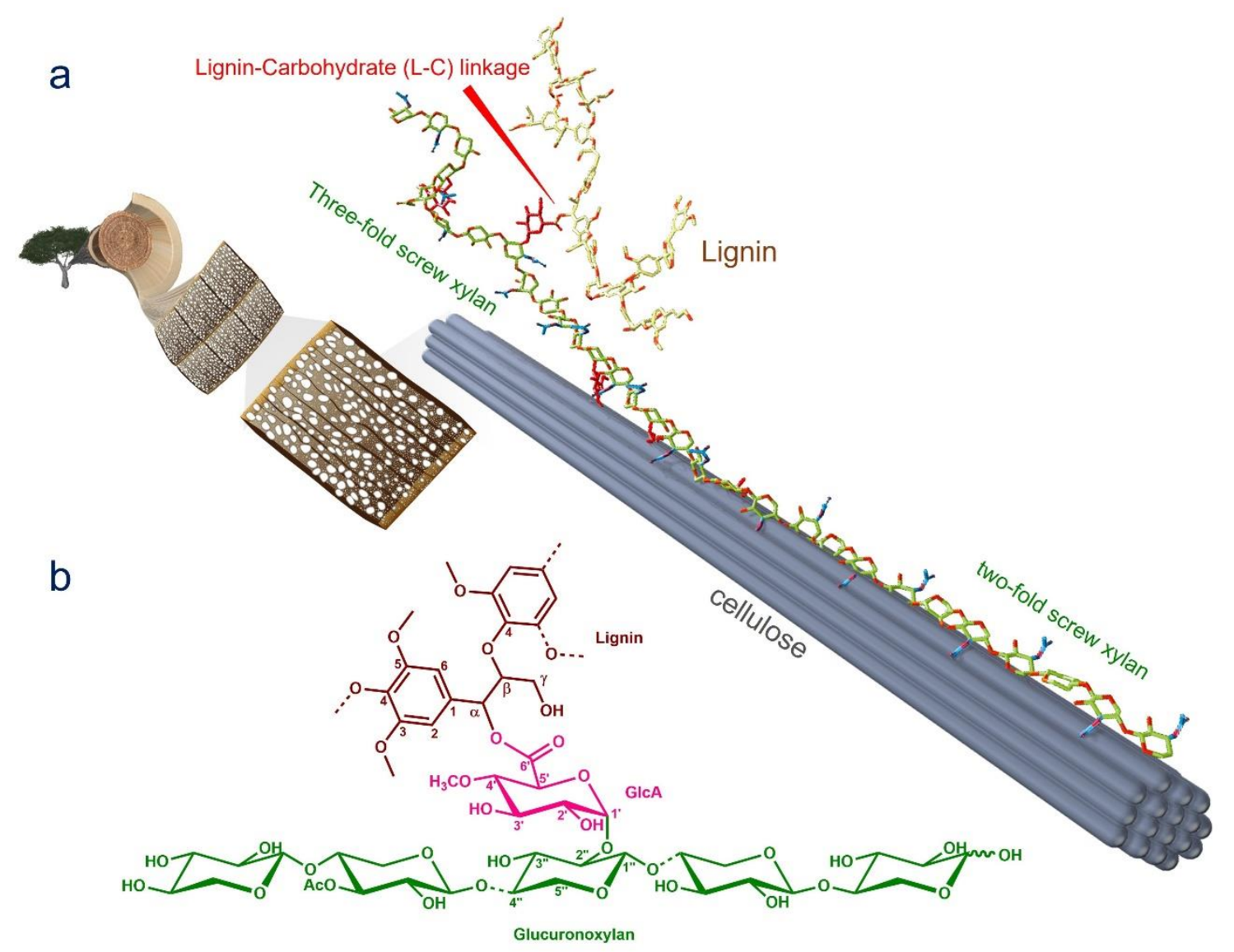

496

497

498

499

500

501

502

503

504

505

506

Fig. 1 Conceptual diagram of a lignocellulosic fibre in hardwood cell walls and the elucidated structural model of the $\alpha$-ester lignin-xylan linkage of lignin-carbohydrate complex (LCC). a, This study determined the principal ester linkages between lignin and xylan (hemicellulose) at the $\alpha$-position of the lignin $\beta$-ether units, as shown in red. Glucurono-xylan covalently bonds with lignin, with an amorphous three-fold screw conformation. In contrast, glucuronoxylan is associated with crystalline cellulose by non-covalent bonds with a two-fold screw conformation. b, The ester bond between the 6-position of $4^{\prime}-O$-methyl glucuronate of glucuronoxylan and the $\alpha$ (benzyl) position of lignin $\beta-O-4^{\prime}$ units are the primary L-C cross-linked structure of lignocellulose. 

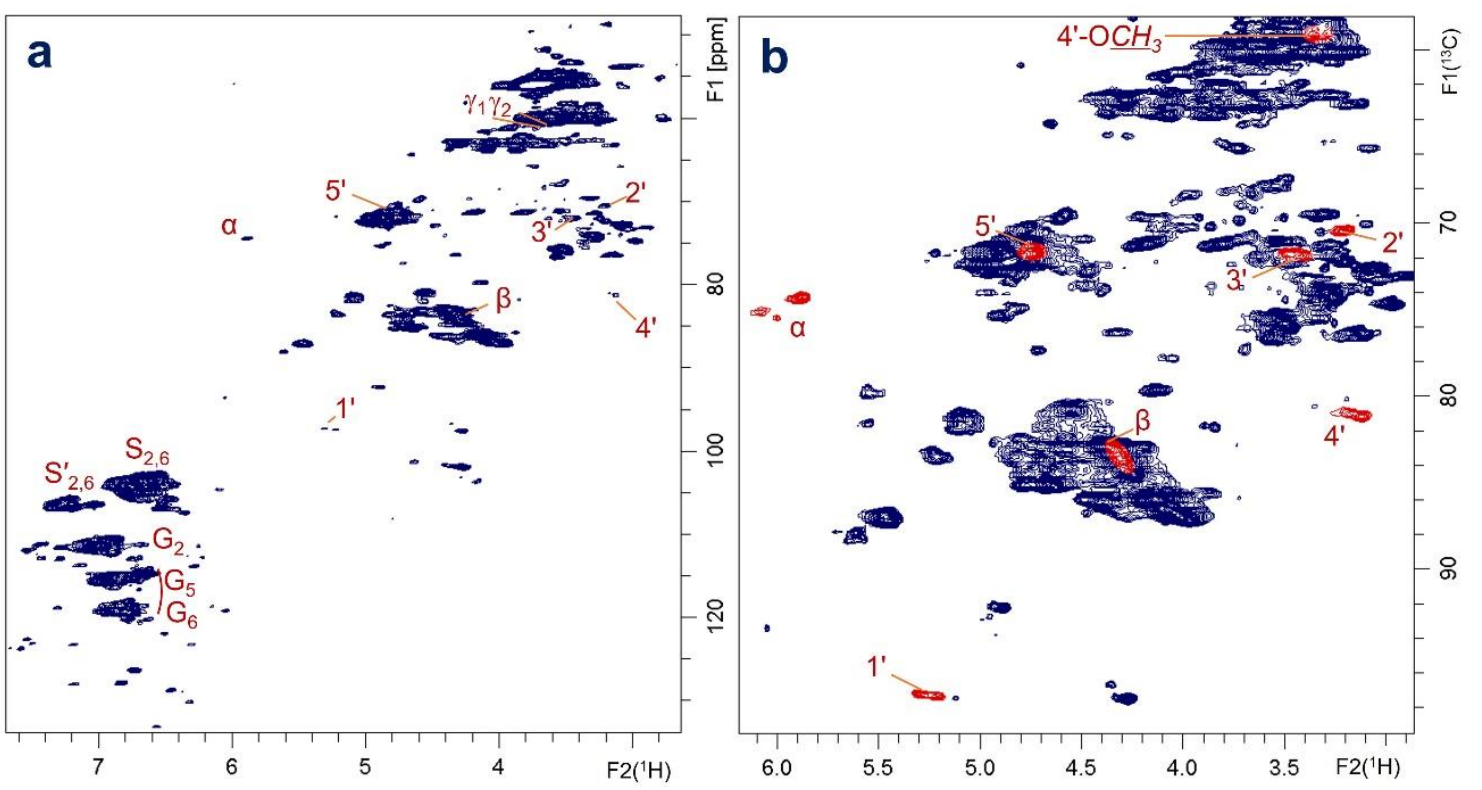

Fig. 2 | The 2D ${ }^{1} \mathrm{H}-{ }^{13} \mathrm{C}$ HSQC spectrum of the $\alpha$-ester-type LCC. a, Full, and a magnified (b) region of the spectrum. Signal assignments originating from $\alpha$-ester L-C linkages are labelled in (a) and (b). Particular signals are labelled and highlighted in red in (b). 

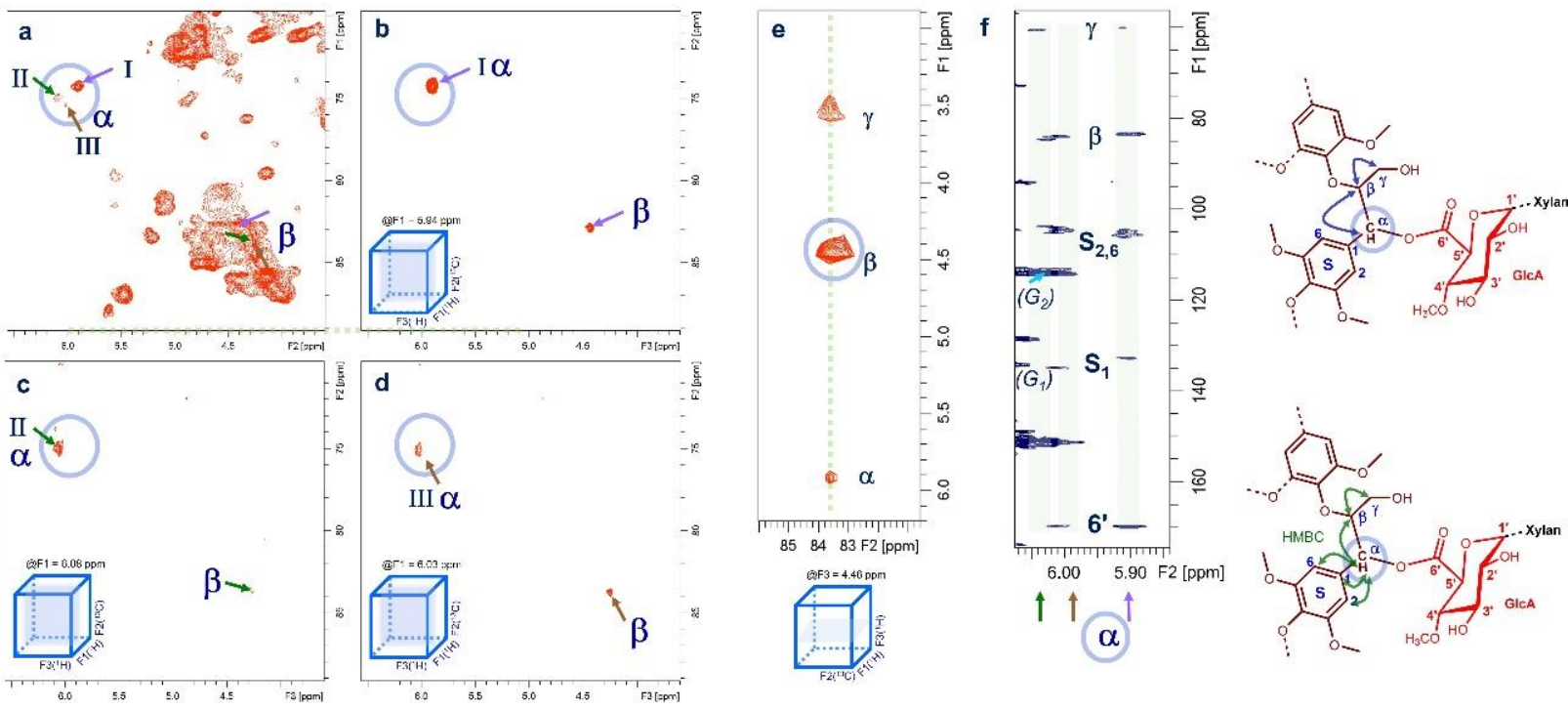

Fig. 3 Reliable signal attribution of the $\alpha$-ester-type LCC by multi-dimensional correlation NMR. The $\alpha$ and $\beta$ correlations in the $2 \mathrm{D}{ }^{1} \mathrm{H}-{ }^{13} \mathrm{C}$ HSQC $(\mathbf{a})$ and 3D TOCSY-HSQC spectra $(\mathbf{b}-\mathbf{d})$ for the lignin $\beta$-aryl ether unit in the $\alpha$-ester-type LCC. Three signals were observed for the $\alpha$-position of the lignin $\beta$-aryl ether unit of L-C ester linkages (circled in a). The extracted planes at each $\alpha$-position in the 3D TOCSY-HSQC spectrum identified each $\beta$-position (b-d). Correlations labelled as I, II, and III are distinguished by arrows (I: purple (b); II: green (c); III: brown (d)). In each case, a signal from a TOCSY correlation from the $\alpha$-position to the $\beta$-position was observed, which was unresolved in the $2 \mathrm{D}^{1} \mathrm{H}-{ }^{13} \mathrm{C}$ HSQC spectrum. e, The extracted plane from the 3D TOCSY-HSQC at the $\beta$ position of the lignin $\beta$-aryl ether unit of L-C ester linkages. TOCSY correlations to the $\alpha$ - and $\gamma$-positions were observed. f, In the $2 \mathrm{D}{ }^{1} \mathrm{H}-{ }^{13} \mathrm{C}$ HMBC spectrum, correlation signals between the $\alpha$-proton of the L-C ester to the $\beta$ and $\gamma$-carbons of the lignin $\beta$-aryl ether unit and syringyl aromatic ring $\left(S_{1}\right.$ and $\left.S_{2,6}\right)$ were observed. The aromatic ring proximity to the $\alpha$-position is mainly the syringyl lignin, and signals from the guaiacyl units were very weak. 


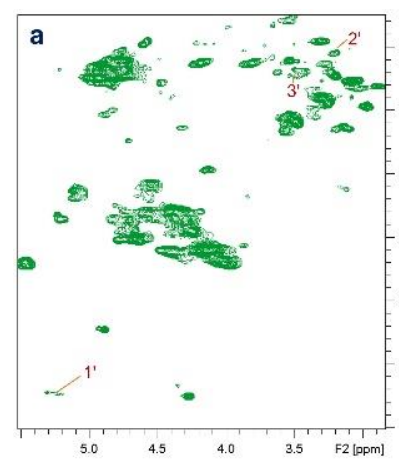

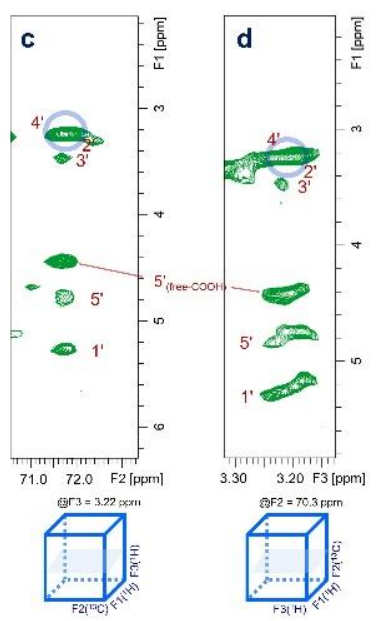

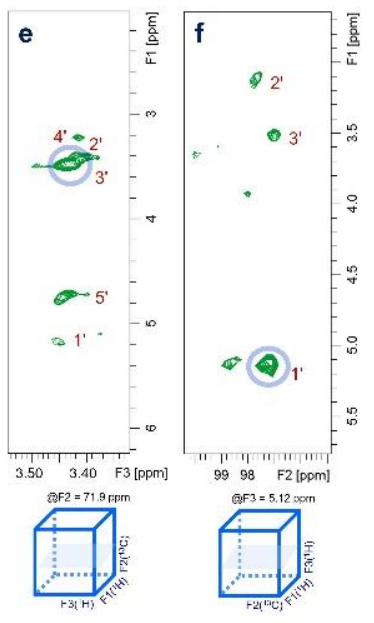

Fig. 4 | Correlation signals of $\mathbf{4}^{\prime}$ - $\boldsymbol{O}$-methyl glucuronate moiety from L-C ester linkages in the LCC sample. $2 \mathrm{D}$ ${ }^{1} \mathrm{H}-{ }^{13} \mathrm{C}$ HSQC spectrum (a) and selected 2D planes from the 3D TOCSY-HSQC spectrum (b-f). b, Extracted plane from the 3D TOCSY-HSQC spectrum showing the anomeric hydrogen at the 1' position of the glucuronic acid (5.19 ppm). TOCSY correlations with GlcA2 and GlcA3 were observed, and the $2 \mathrm{D}{ }^{1} \mathrm{H}-{ }^{13} \mathrm{C}$ HSQC spectrum (a) displays the same spectral region for comparison. d, Extracted region of the 3D TOCSY-HSQC showing the signal from the hydrogen at GlcA2 (3.20 ppm), and extracted region in (c) showing the correlation to the carbon in GlcA2 (70.3 ppm). TOCSY correlation signals from GlcA1 to GlcA5 were observed in each case. The chemical shifts of the signals arising from the hydrogens in GlcA2 and GlcA4 partially overlap. e, Extracted region from the 3D TOCSYHSQC showing the signal arising from the carbon (71.9 ppm) of GlcA3. TOCSY correlation signals from GlcA1 to GlcA5 were observed. f, Extracted region from the 3D TOCSY-HSQC showing correlation signals for the hydrogen in GlcA1. TOCSY correlation signals from GlcA1 to GlcA2 and GlcA3 were observed. 

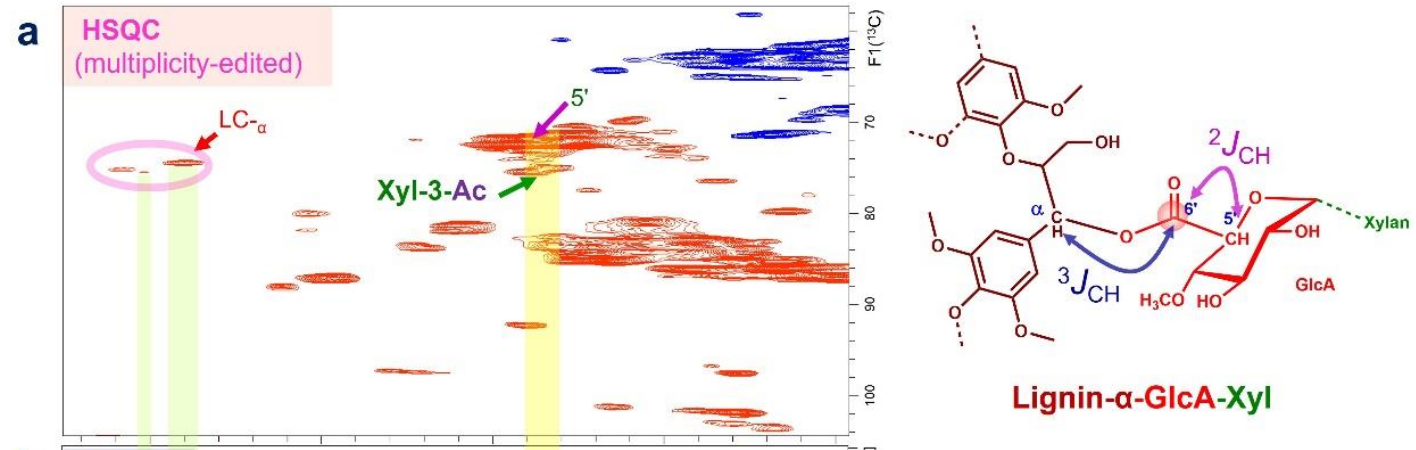

b

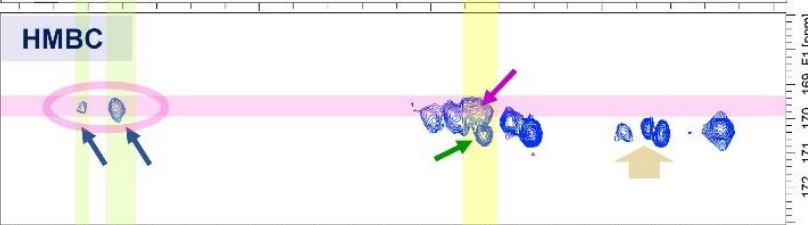

c

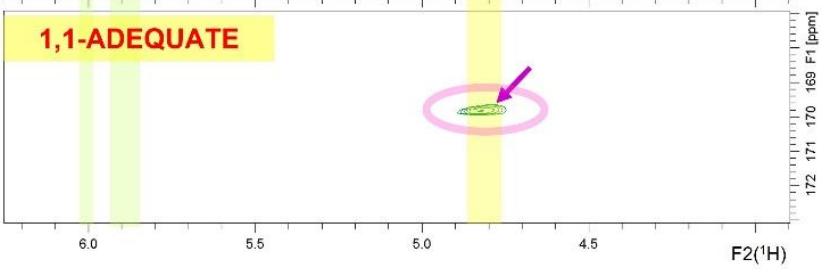

Lignin- $\alpha-G \mid c A-X y l$

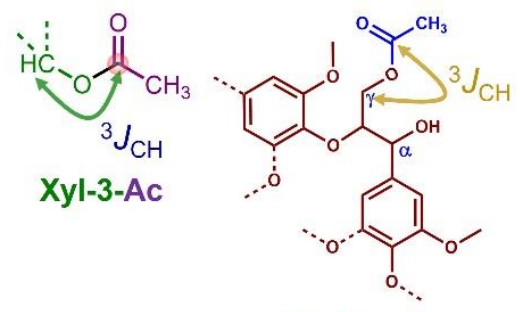

Lignin-y-Ac

Fig. 5 | Clear evidence of an $\alpha$-ester-type LCC using 2D 1,1-ADEQUATE and HMBC spectra. The multiplicity-edited HSQC spectrum (a), HMBC spectrum (b), and 1,1-ADEQUATE spectrum (C) are shown. b, In the HMBC spectrum, there is a correlation between the carbonyl carbon at $169.6 \mathrm{ppm}$ and the $\alpha$-position of LCC shown in the HSQC spectrum (a). This carbon $\left(\delta_{\mathrm{C}} 169.6 \mathrm{ppm}\right)$ correlates with the signal at $\delta_{\mathrm{H}} 4.8 \mathrm{ppm}$ in $(\mathbf{b})$. a, The acetyl-substituted xylan at the 3-position (Xyl-3-Ac) and the glucuronate moiety at the 5-position in LC glucuronoxylan have almost the same $\delta_{\mathrm{H}}$ of $4.8 \mathrm{ppm}$. c, In the 1,1-ADEQUATE spectrum, only the correlation signal derived from ${ }^{2} J_{\mathrm{CH}}$ is detected. Therefore, the correlation signal with the carbonyl group of the ester type LC bond was clearly distinguished from acetyl-substituted xylan at the 3-position. Signals at $\delta_{\mathrm{H}} 4.3-4.4 \mathrm{ppm}$ in (b) represent correlations between the proton at the $\gamma$ position and the carbonyl carbon. No 1,1-ADEQUATE correlation derived from the $\gamma$-ester-type LCC was observed and was identified as a $\gamma$-acetyl substituted lignin unit. 


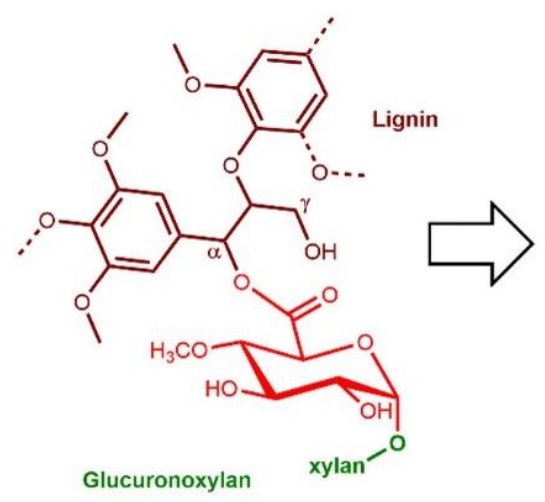

$\alpha$-ester LC linkage
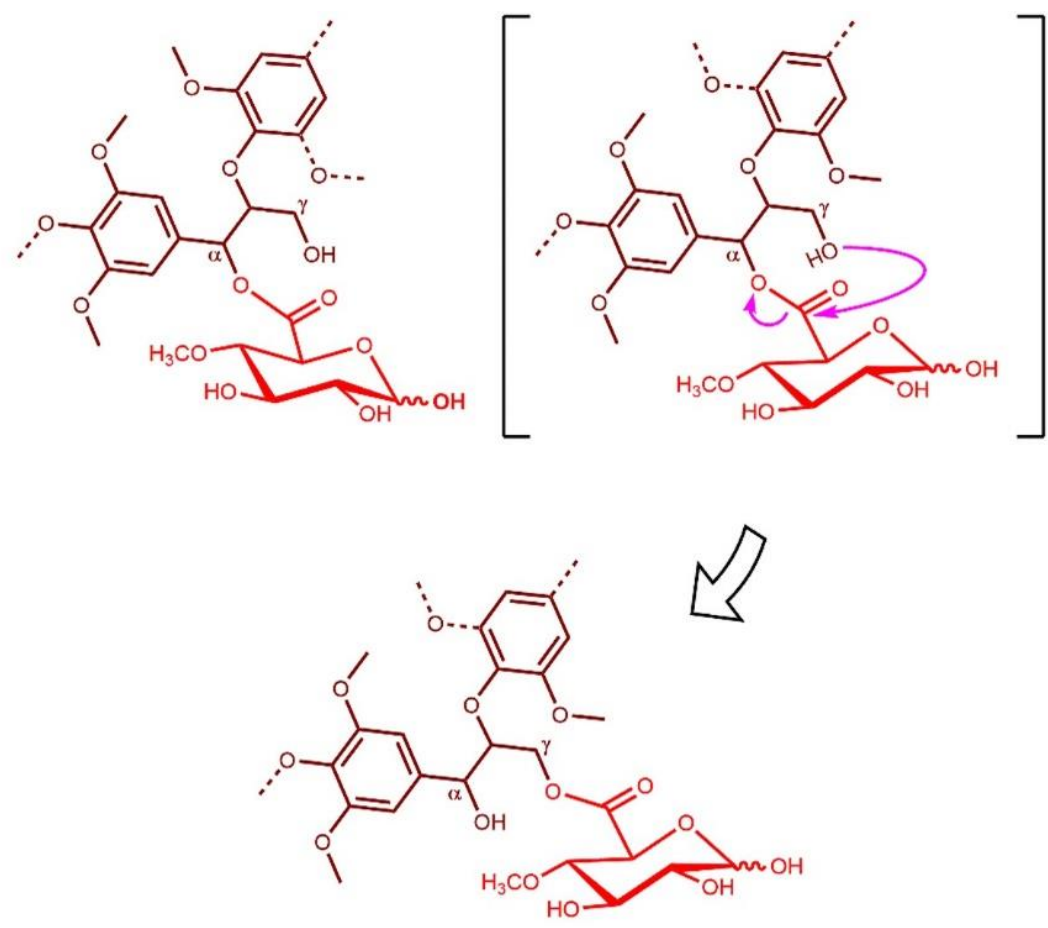

$\gamma$-ester L-C linkage

Fig. 6 | Proposed rearrangement reaction of $\boldsymbol{\alpha}$-ester LCC to $\boldsymbol{\gamma}$-ester LCC. Original L-C linkage at the $\alpha$-position of the lignin aryl ester unit on LCC migrates to the $\gamma$-position. The migration may arise from artificial degradation; partial bond-cleavage of glucuronoxylan in LCC during sample preparation, e.g., ball-milling and heat, chemical, and enzymatic treatments. 
Extended Table 1 | NMR signal assignments of the $\alpha$-ester-type LCC.

\begin{tabular}{|c|c|c|c|}
\hline Labels & $\delta_{\mathrm{H}}(\mathrm{ppm})$ & $\delta_{\mathrm{C}}(\mathrm{ppm})$ & Assignments \\
\hline $\mathrm{I}-\alpha$ & 5.88 & 74.4 & $\begin{array}{l}\alpha \text {-CH of } \beta-O-4^{\prime} \text { substructures in } \alpha \text {-ester-type LCC linked to } \\
\text { esterified syringyl units }\end{array}$ \\
\hline II- $\alpha$ & 6.08 & 75.2 & $\begin{array}{l}\alpha-\mathrm{CH} \text { of } \beta-O-4^{\prime} \text { substructures in } \alpha \text {-ester-type LCC linked to } \\
\text { free phenolic syringyl units }\end{array}$ \\
\hline III- $\alpha$ & 6.00 & 75.5 & $\begin{array}{l}\alpha \text {-CH of } \beta-O-4^{\prime} \text { substructures in } \alpha \text {-ester-type LCC linked to } \\
\text { guaiacyl } 1 \text { units }\end{array}$ \\
\hline $\mathrm{I}-\beta$ & 4.48 & 82.9 & $\begin{array}{l}\beta \text {-CH of } \beta-O-4^{\prime} \text { substructures in } \alpha \text {-ester-type LCC linked to } \\
\text { esterified syringyl units }\end{array}$ \\
\hline II $-\beta$ & 4.28 & 83.7 & $\begin{array}{l}\beta-\mathrm{CH} \text { of } \beta-O-4^{\prime} \text { substructures in } \alpha \text {-ester-type LCC linked to } \\
\text { free phenolic syringyl units }\end{array}$ \\
\hline III- $\beta$ & 4.28 & 83.9 & $\begin{array}{l}\beta-\mathrm{CH} \text { of } \beta-O-4^{\prime} \text { substructures in } \alpha \text {-ester-type LCC linked to } \\
\text { guaiacyl } 1 \text { units }\end{array}$ \\
\hline$\gamma_{1}, \gamma_{2}$ & $3.55,3.83$ & $61.0 / 62.0$ & $\gamma-\mathrm{CH}_{2}$ of $\beta-O-4^{\prime}$ substructures in $\alpha$-ester-type \\
\hline 1'-GluA & $\begin{array}{c}5.19 \\
(5.13- \\
5.31)\end{array}$ & $97.2-97.5$ & $\begin{array}{l}1^{\prime}-\mathrm{CH} \text { (anomeric position) in } 4 \text { '- } O \text {-methyl glucuronic acid in } \\
\alpha \text {-ester-type LCC }\end{array}$ \\
\hline 2'-GluA & 3.20 & 70.3 & $2^{\prime}-\mathrm{CH}$ in 4'-O-methyl glucuronic acid in $\alpha$-ester-type LCC \\
\hline 3'-GluA & 3.43 & 71.9 & $3^{\prime}-\mathrm{CH}$ in 4'-O-methyl glucuronic acid in $\alpha$-ester-type LCC \\
\hline 4'-GluA & $3.12-3.24$ & 81.13 & $4^{\prime}-\mathrm{CH}$ in $4^{\prime}-O$-methyl glucuronic acid in $\alpha$-ester-type LCC \\
\hline 5'-GluA & 4.80 & 71.7 & $5^{\prime}-\mathrm{CH}$ in $4^{\prime}-\mathrm{O}$-methyl glucuronic acid in $\alpha$-ester-type LCC \\
\hline 6'-GluA & - & 169.7 & $6^{\prime}-\mathrm{C}=\mathrm{O}$ in $4^{\prime}-O$-methyl glucuronic acid in $\alpha$-ester-type LCC \\
\hline$\frac{\mathrm{CH}_{3}-4^{\prime}-}{\text { GluA }}$ & 3.32 & 59.2 & $\begin{array}{l}\text { Methoxy } \mathrm{CH}_{3} \text { in } 4 \text { '-O-methyl glucuronic acid moiety of } \\
\text { glucuronoxylan }\end{array}$ \\
\hline $\mathrm{S}_{2,6}$ & $6.61-670$ & $\begin{array}{c}103.4- \\
105.1\end{array}$ & $\mathrm{C}_{2}-\mathrm{H}_{2}$ and $\mathrm{C}_{6}-\mathrm{H}_{6}$ in syringyl units \\
\hline $\mathrm{S}_{2,6}^{\prime}$ & $7.19-7.32$ & $\begin{array}{c}105.9- \\
106.7\end{array}$ & $\mathrm{C}_{2}-\mathrm{H}_{2}$ and $\mathrm{C}_{6}-\mathrm{H}_{6}$ in $\alpha$-oxidized syringyl units \\
\hline $\mathrm{S}_{1}$ & - & $\begin{array}{c}132.7 / 134 \\
7\end{array}$ & $\mathrm{C}_{1}$ in syringyl units (etherified units/free phenolic units) \\
\hline $\mathrm{G}_{2}$ & 6.99 & 111.3 & $\mathrm{C}_{2}-\mathrm{H}_{2}$ in guaiacyl units (centre of width in signals) \\
\hline $\mathrm{G}_{5}$ & 6.95 & 115.4 & $\begin{array}{l}\mathrm{C}_{5}-\mathrm{H}_{5} \text { (containing minor } \mathrm{C}_{6}-\mathrm{H}_{6} \text { in part) in guaiacyl units } \\
\text { (centre of width in signals) }\end{array}$ \\
\hline $\mathrm{G}_{6}$ & 6.75 & 119.3 & $\mathrm{C}_{6}-\mathrm{H}_{6}$ in guaiacyl units (centre of width in signals) \\
\hline
\end{tabular}

Abbreviations:

LCC, $\alpha$-ester (benzyl ester)-type lignin-carbohydrate complex; G, guaiacyl lignin units; Chemical shift values are taken at the centre of the signals 


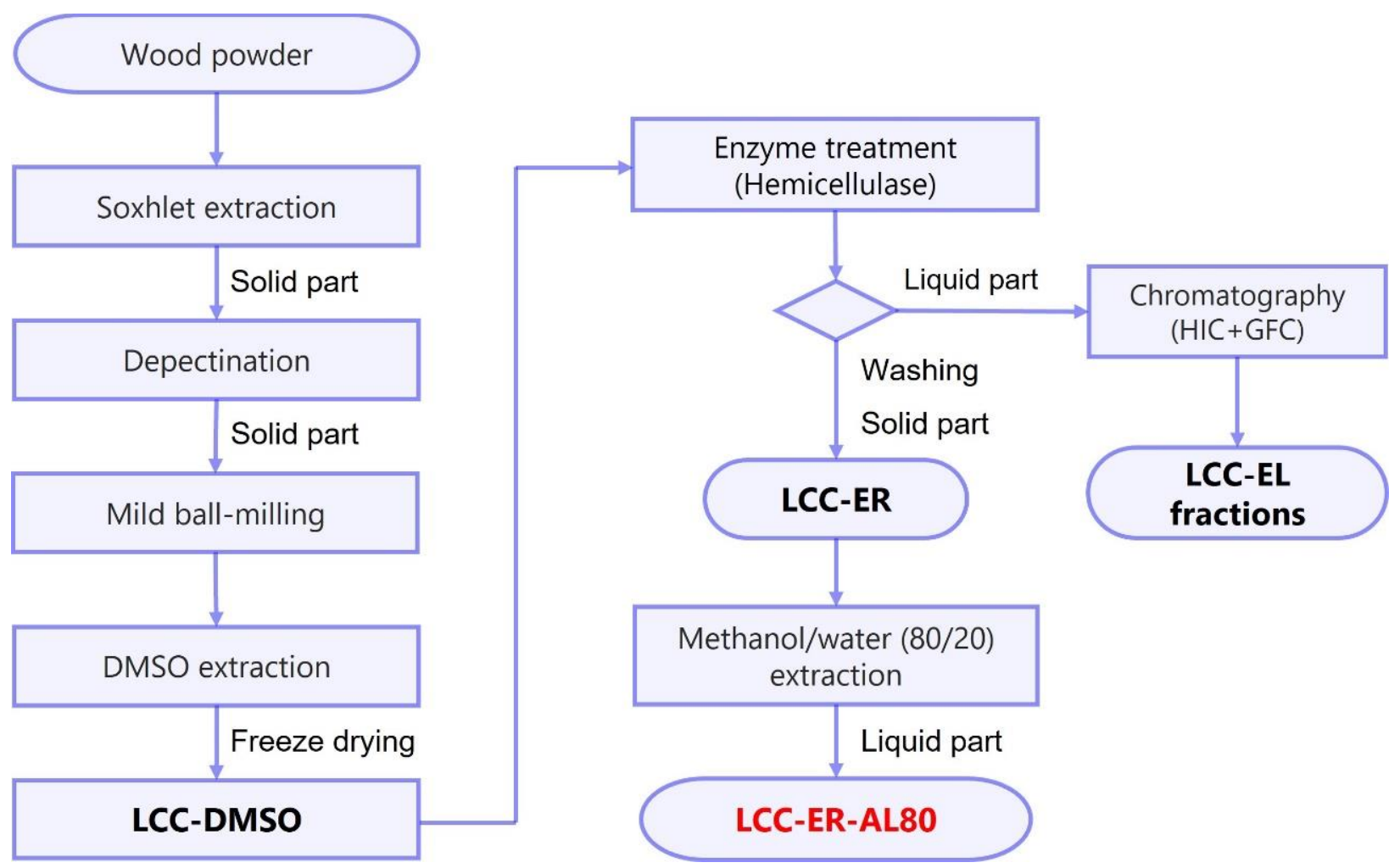

566 567

Extended Data Fig. 1 | A flow diagram of the LCC sample fractionation process. 
a

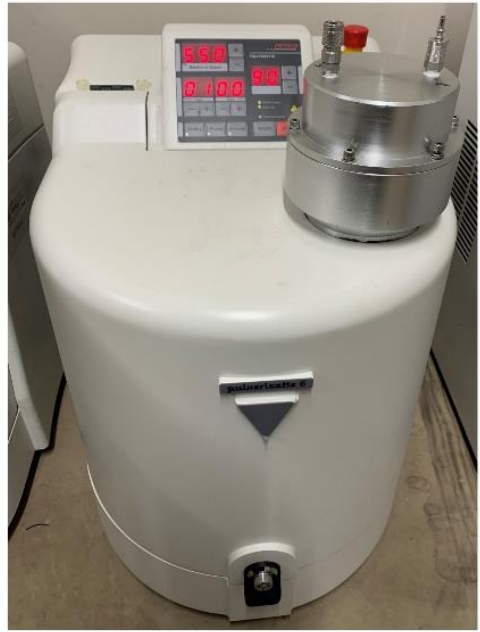

b

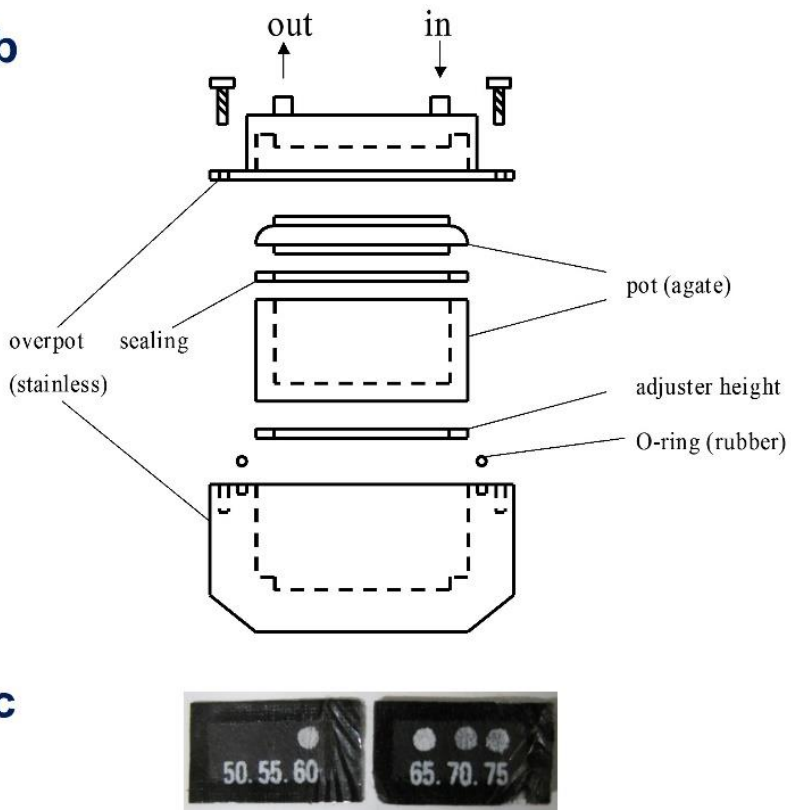

Extended Data Fig. 2 | Planetary ball-milling treatment performed under mild conditions for LCC sample preparation. a, Photograph of the planetary ball-milling equipment, PULVERISETTE 6 and the overpot system (shown on the device). b, A schematic of the overpot system. The agate pot vessel is set in the overpot. c, Photograph of the thermo label after ball-milling, showing that the treatment was conducted at $60^{\circ} \mathrm{C}$. The temperature was monitored during ball-milling, and irreversible thermal labels were pasted on the bottom of the agate pot. 

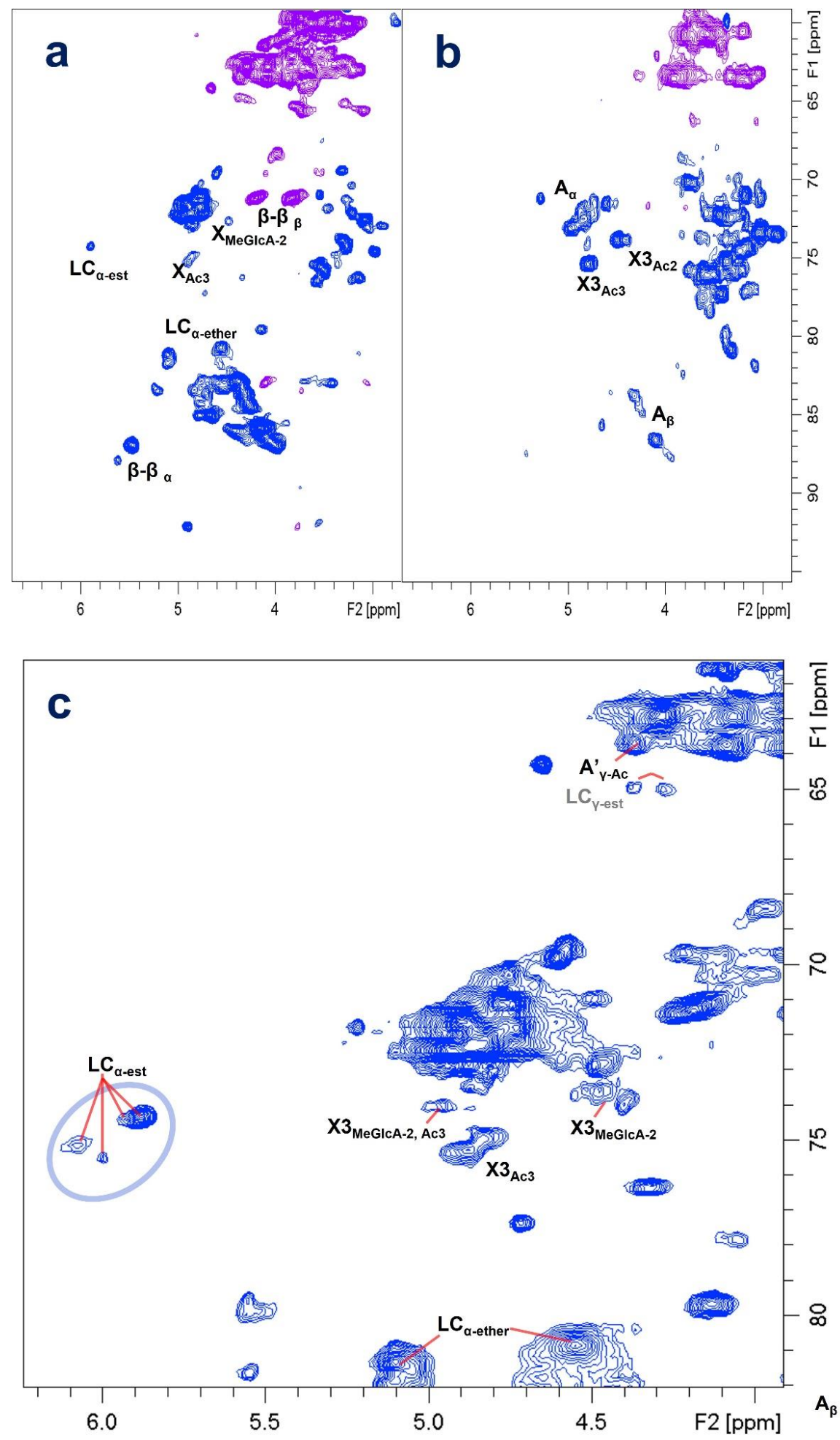

Extended Data Fig. 3 | NMR data of LCC-ER-AL80 and LCC-DMSO. Multiplicity-edited $2 \mathrm{D}{ }^{1} \mathrm{H}-{ }^{13} \mathrm{C}$ NMR spectra of (a) LCC-ER-AL80 extracted by methanol/water, followed by enzymatic treatment, and (b) crude extracts of LCC-DMSO. c, Expanded region of the $2 \mathrm{D}{ }^{1} \mathrm{H}-{ }^{13} \mathrm{C}$ HSQC spectrum of LCC-ER-AL80. 